\title{
O Uso do Fórum em Um curso de Graduação a Distância: Formação e Aprendizagem
}

\author{
Amanda Barbosa da Silva \\ Universidade Federal de Pernambuco (UFPE) - Avenida Prof. Moraes Rego, \\ 1235 -50670-901- Cidade Universitária- Recife - PE - Brasil \\ amanda mat123@hotmail.com
}

\begin{abstract}
The text is the result of a research with four graduating classes of the degree course in Pedagogy in the distance modality. The main objective of the research is to reflect on the mathematical formation of the graduates from the use of the Forum as a tool to promote learning. The groups responded to activities in their respective forums, then the answers were analyzed in order to evaluate how the learning in the proposed activities is related to the formation of the student and to the use of the forum as a pedagogical tool. The results indicate that the forum favored the reflection about the subjects' formation and the interaction in the environment provided learning.
\end{abstract}

Resumo. O texto é resultado de uma pesquisa com quatro turmas concluintes do curso de licenciatura em Pedagogia na modalidade a distância. A pesquisa tem como principal objetivo refletir sobre a formação matemática dos graduandos a partir do uso do Fórum como ferramenta para favorecer a aprendizagem. As turmas responderam atividades em seus respectivos fóruns, em seguida as respostas foram analisadas com o objetivo de avaliar como a aprendizagem nas atividades propostas está relacionada a formação do discente e ao uso do fórum como ferramenta pedagógica. Os resultados apontam que o fórum favoreceu a reflexão sobre a formação dos sujeitos e a interação no ambiente proporcionou aprendizagens.

\section{Introdução}

Este artigo apresenta os resultados de uma pesquisa desenvolvida com quatro turmas do curso de Licenciatura em Pedagogia na modalidade a distância, tendo como principal objetivo analisar o uso do fórum como ferramenta pedagógica para favorecer a aprendizagem no ambiente virtual de aprendizagem (AVA). A atividade foi realizada 
durante a disciplina de Metodologia do Ensino de Matemática e consiste de três questões referentes a conteúdos de Geometria dos anos iniciais. As questões foram selecionadas com o intuito de favorecer a reflexão sobre o ensino e a aprendizagem de Geometria no Ensino Fundamental, tal conteúdo faz parte da prática de ensino dos futuros docentes e também contempla os tópicos da disciplina.

O fórum foi escolhido para realização da atividade por ser uma ferramenta do AVA onde é possível estabelecer uma comunicação assíncrona, ou seja, não é necessário que professor e aluno estejam conectados simultaneamente. Os fóruns são bons exemplos desse tipo de comunicação, os tutores e os professores podem criar os tópicos de discussão nos fóruns e todos podem participar da discussão no momento em que tiver disponibilidade. Segundo Lima, Rodrigues e Viana (2016) há uma necessidade de melhorar a interação e comunicação entre alunos e professores no AVA, considerando a usabilidade do recurso e a possibilidade de interação síncrona e assíncrona, o fórum foi considerado uma boa opção para analisar a interação dos alunos no AVA e sua relação com a aprendizagem.

\section{Metodologia}

A Metodologia utilizada é do tipo exploratória e descritiva tendo como base uma interpretação qualitativa dos dados coletados na atividade proposta. A atividade proposta no fórum apresentava três questões, as duas primeiras questões foram selecionadas com o objetivo de verificar como os discentes de Pedagogia resolviam questões sobre conteúdos de Geometria dos anos iniciais do ensino fundamental, pois são conceitos que os futuros docentes irão lecionar. Na última questão foi solicitado aos sujeitos uma análise das duas primeiras questões, tal questionamento permitiu que o aluno se coloque de forma autônoma e livre para comentar sobre o fórum proposto, além de expor também sua compreensão acerca dos conteúdos trabalhados.

A primeira questão, Figura 1 abaixo, é um recorte de um livro didático de Matemática. A questão apresenta como tema principal o estudo da abertura de ângulo, para responder corretamente a primeira questão, o aluno deveria indicar a letra $\mathrm{C}$ como sendo o giro de uma volta, a letra A para o giro de meia volta e a letra D para o giro de um quarto de volta.

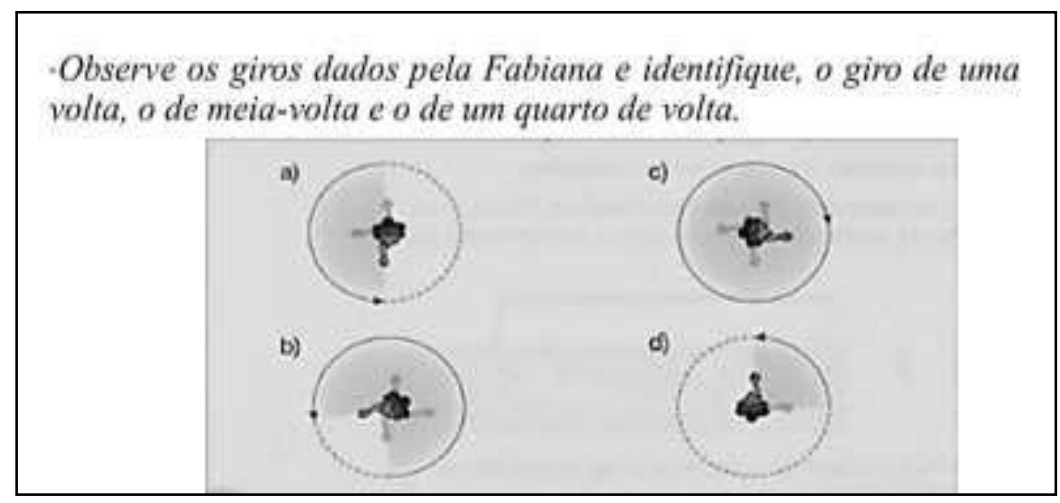

Figura 1: Primeira questão da atividade

Fonte: GAY, Maria. Projeto Buriti. 5o ano. Editora Moderna, 2011, p.72 
A segunda questão, Figura 2 abaixo, foi escolhida por ser um dos exemplos utilizados na Prova Brasil de Matemática para os alunos do quinto ano do ensino fundamental.

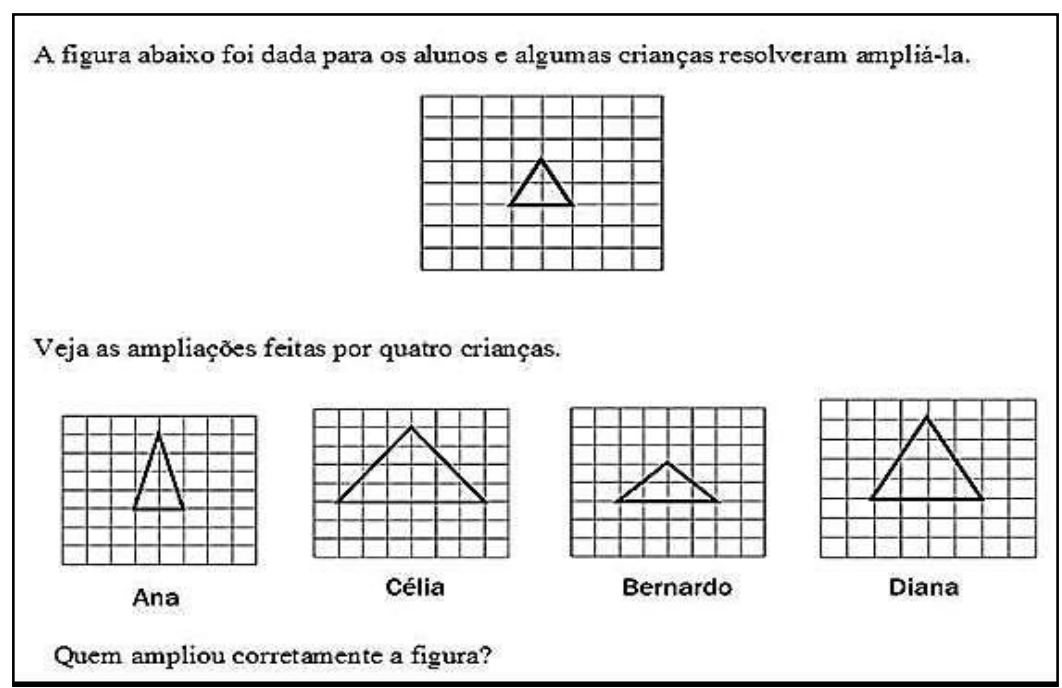

Figura 2: Segunda questão da atividade

\section{Fonte: Caderno da Prova Brasil. Ensino Fundamental. Matrizes de Referência, Tópicos e Descritores, 2011, p.110.}

A última questão solicitou a opinião dos graduandos sobre os conceitos de Geometria que foram trabalhados na atividade e como os futoros docentes poderiam ajudar os estudantes do quinto ano a compreenderem as duas primeiras questões.

Questão três:

a. Cite alguns aspectos conceituais da Geometria que estão presentes nas duas questões.

b. Que possíveis dificuldades um aluno do $5^{\circ}$ ano teria para resolver as questões? Como poderíamos ajudá-lo?

\section{Resultados e Discussão}

Foram identificados os comentários mais frequentes nas postagens dos licenciandos, o que resultou num total de 143 postagens referente às respostas das quatro turmas. Para cada turma foi apresentado um fórum de Geometria com as três questões da atividade. Em relação a primeira questão, os licenciandos utilizaram diferentes representações e foram encontradas respostas erradas nas quatro turmas, pois vários alunos demonstraram incompreensão sobre conceitos básicos da Geometria.

Percebemos que a primeira questão permitiu uma variedade significativa de interpretações, o que pode ser constatado pelas diferentes representações utilizadas pelos graduandos. Além disso, nas respostas das quatro turmas há erros que se repetem e que demonstram uma evidente incompreensão de conceitos básicos da Geometria, o que indica uma formação matemática insuficiente para lecionar nos anos iniciais. Tal resultado nos 
remete aos estudos de Curi (2004), onde afirma que ementas das disciplinas de Matemática dos cursos de Pedagogia apresentam atenção para os conteúdos de Geometria.

As quatro turmas possuíam professores virtuais que auxiliavam na resolução da atividade e todos receberam as devidas orientações. Porém, as quatro turmas apresentaram uma repetição de erros envolvendo conceitos que são trabalhados ainda nos anos iniciais do ensino fundamental, tais como, representação fracionária, o uso de giros e voltas associados ao conceito de ângulo e a ideia de grau como unidade de medida.

O licenciando três tentou identificar todas as voltas, porém recorreu à unidade de medida grau para responder. O licenciando três associou corretamente os graus e as voltas em todas as alternativas. Apesar da primeira questão não sugerir o uso do grau, o estudante relacionou corretamente o conceito de ângulo com a ideia de giros e voltas.

Licenciando 3 (Turma 2): Observando os giros dados por Fernanda, identifica-se que:
a) Ela girou $180^{\circ}$ graus;
b) Ela girou $180^{\circ}+90^{\circ}=270^{\circ}$
c) Ela girou $360^{\circ}$ graus
d) Ela girou $90^{\circ}$ graus

O licenciando quatro identificou corretamente as três voltas solicitadas na questão e utilizou a representação fracionária em suas respostas. Apesar de não optar pelo uso do grau, o licenciando quatro demonstrou compreender o significado dos giros apresentados na questão.

Licenciando 4 (Turma 4): Na primeira questão encontrei as seguintes respostas
a) $1 / 2$ volta,
c) 1 volta
d) $1 / 4$ de volta

O licenciando cinco cometeu vários erros ao associar o número de voltas e a representação fracionária. Os giros de meia volta e de uma volta foram indicados corretamente nas alternativas A e C, porém o licenciando errou nas alternativas B e D. A alternativa B representa três quartos e não "três de todo de uma volta" e a alternativa $\mathrm{D}$ representa um quarto de volta, logo o estudante não compreende como representar as voltas na questão e nem como escrever corretamente em forma de fração.

\section{Licenciando 5 (Turma 1):}

a) Ela realizou 2/4 dois quartos da volta que reduzindo (dividindo) por 2 equivale

a $1 / 2$ um meio, ou seja, meia volta.

b) Ela realizou 3/1 três de um todo da volta.

c) Ela realizou 4/4 quatro quartos da volta que reduzido (dividindo) por 4 equivale a 1 , ou seja, uma volta completa.

Ela realizou $4 / 4=1$ volta completa 
Verificamos que todos os estudantes acertaram a segunda questão, pois optaram alternativa D que indica Diana como a ampliação correta da figura. Tal resultado pode está relacionado a diversidade de conceitos e representações possíveis para a primeira questão, tais como fração, giros, voltas, ângulos, grau e circunferência. Já na segunda questão, o próprio recurso da malha quadriculada facilitou a visualização da alternativa correta.

$\mathrm{Na}$ terceira questão os licenciandos puderam refletir sobre as duas primeiras questões, o objetivo desse questionamento foi promover a reflexão sobre o ensino de Geometria a partir da opinião dos próprios licenciandos e levantar uma reflexão crítica sobre formação e autoavaliação. Um dos alunos da turma dois comentou o seguinte no fórum: "Para ajudar o aluno a construir o conceito de ângulo é interessante explorar situações do seu cotidiano, brincadeiras e o uso do seu próprio corpo. Atividade: Construir um ângulo com duas tiras de papelão (de cores diferentes) e um percevejo 1 para trabalhar com os giros. Desenhar ampliações e reduções de figuras planas em malha quadriculada. Trabalhar com malha quadriculada, trabalhando a questão da proporcionalidade".

A seguir observamos que o licenciando nove, apesar de não responder especificamente o que solicitava a terceira questão, apresentou uma reflexão importante sobre o ensino de Geometria. Em sua postagem, apresentada abaixo o licenciando percebeu a necessidade de ampliar o trabalho com a Geometria na educação infantil.

Licenciando 9 (Turma 2): Através destas atividades percebemos que o estudo da Geometria na Educação Infantil deve ir além de conhecer as formas geométricas e nomeá-las. É necessário que o professor possibilite à criança, viver, perceber e conceber o espaço. O conhecimento da Geometria auxilia ao entendimento do campo numérico, de trabalhos que envolvam conceitos de perímetros, áreas, volumes e na construção de maquetes, tabelas e gráficos. Isso justifica sua importância durante todo o ano letivo para benefício do aluno. Para que quando surjam situações como estas o aluno não encontre dificuldade para solucioná-las. O trabalho tem que começar na base!

Foram encontrados comentários coerentes com os conceitos presentes nas questões, mas também respostas que demonstram uma incompreensão acerca dos conceitos básicos envolvidos na atividade. Por exemplo, na postagem do licenciando onze, o graduando relacionou aspectos conceituais que não estão presentes nas duas primeiras questões.

Licenciando 11 (Turma 3): Aspectos conceituais questão um: Sólido geométrico, círculo, noção de fração, ângulo, localização espacial. Para os alunos entenderem este desafio poderíamos desenhar um círculo no chão e simular as alternativas de respostas do problema proposto, para resolver o desafio coletivamente. Aspectos conceituais na questão dois: Espaço e forma. O professor deve explicar que, quando alguém amplia ou reduz uma figura a forma e mantida.

A resposta do licenciando doze representa grande parte das postagens que foram encontradas no fórum da turma quatro. 
Licenciando 12 (Turma 4): a) Conceitos presentes na atividade: Simetria, ângulo, regularidade, triângulos, semirreta, vértices, arestas, tempo etc. b) $\mathrm{O}$ professor deverá levar régua para desenharem os uma semirreta e desenhar os triângulos, como também fazer associações com objetos que tem o mesmo formato. Levar vários tangrans para entenderem a redução de triângulos como também mosaicos e papel milimetrado para fazer as atividades propostas. Usando esses materiais a aula ficaria mais lúdica e prazerosa fazendo com que os alunos participem ativamente da aula.

Assim como nas turmas anteriores, os graduandos da turma quatro mencionaram a presença de aresta, demonstrando uma incompreensão para diferenciar elementos básicos da Geometria Plana e da Geometria Espacial. Os resultados indicaram que a atividade motivou os estudantes, pois houve uma interação contínua nos fóruns e as quatro turmas responderam todas as questões. As interações no AVA indicam que o uso da ferramenta fórum proporcionou uma participação ativa dos alunos na atividade, as discussões nos fóruns das quatro turmas foram além do conteúdo matemático trabalhado, os alunos passaram a refletir de forma crítica sobre sua própria formação, identificando as lacunas que possuem ao longo de sua trajetória e como é importante superá-las para realizar sua prática professional. Por exemplo, um dos licenciandos fez um comentário relevante sobre a atividade e a formação de professores.

Licenciando 1 (Turma 2): A Geometria não tem lugar reservado no âmbito da Educação Infantil, bem como no curso de formação de professores frequentado por nós. Isso fica evidente na tamanha dificuldade em se trabalhar Geometria, tanto na Educação Infantil quanto no Ensino Fundamental. Devemos ficar atentos à necessidade de uma metodologia que facilite o processo de ensino $\mathrm{e}$ aprendizagem, ressaltando a importância da Geometria em nossas vidas, dando à criança a possibilidade de exploração e para tudo isso se concretizar requer intencionalidade e conhecimento do professor.

Percebemos no comentário acima que a atividade no fórum mobilizou reflexões nos alunos acerca do conteúdo tratado na atividade, mas também uma visão crítica sobre sua formação e proporcionou uma autoavaliação do discente enquanto graduando de licenciatura. Quando consideramos que o licenciando um está concluindo o curso de licenciatura em Pedagogia e afirma que a Geometria não tem lugar reservado na Educação Infantil e tampouco no curso que ele próprio frequenta, tais opiniões reforçam a necessidade de melhorar a formação inicial dos futuros professores, o que já foi apontado por pesquisas anteriores, Curi (2004), Costa, Pinheiro e Costa (2016). 


\section{Considerações Finais}

A atividade proposta, além de contemplar conteúdos da Matemática, também favoreceu a reflexão sobre a formação de professores dos anos iniciais. Diante das questões sobre Geometria os licenciandos não se limitaram apenas a responder as questões, eles também externaram a insatisfação com sua formação superior em relação a pouca ênfase dada a Geometria. A pesquisa deixa evidente a necessidade de mais atenção com a formação matemática dos graduandos em Pedagogia e como o uso do fórum pode favorecer a aprendizagem no AVA, quando apresentamos propostas de atividade que motivam a interação e o debate entre os alunos.

A formação inicial dos professores que atuam nos anos iniciais é de primordial importância, pois são os responsáveis por elaborar as primeiras experiências de ensino e de aprendizagem que os alunos terão na escola. Diante de resultados preocupantes e com o objetivo de contribuir para a formação dos licenciandos, antes de encerrar os fóruns, os tutores virtuais e o professor formador postaram comentários para esclarecer os principais erros cometidos pelos licenciandos. Além dessas intervenções no ambiente virtual de aprendizagem, os licenciandos participaram de uma aula presencial com os tutores virtuais sobre o ensino de Geometria.

A importância de acompanhar a participação dos alunos no ambiente virtual de aprendizagem foi essencial, pois somente com um acompanhamento personalizado e com a avaliação das postagens foi possível detectar a necessidade de uma intervenção maior no fórum e na aula presencial. A pesquisa também mostrou a necessidade de realizar estudos sobre a formação inicial de professores polivalentes, já que tais pesquisas podem contribuir para melhorar a formação matemática dos graduandos.

\section{Referências}

COSTA, Jaqueline de Morais; PINHEIRO, Nilcéia Aparecida Maciel; COSTA, Ercules. A formação para matemática do professor de anos iniciais. Ciênc. educ. (Bauru), Bauru, v. 22, n. 2, p. 505-522, June 2016. Available from $<$ http://www.scielo.br/scielo.php?script=sci_arttext\&pid=S1516-

73132016000200505\&lng=en\&nrm=iso>. Acesso em: 01 Jun 2019.

CURI, Edda. Formação de professores polivalentes: uma análise do conhecimento para ensinar Matemática e de crenças e atitudes que interferem na constituição desses conhecimentos. 2004. 278 f. Tese (Doutorado em Educação Matemática). Faculdade de Educação Matemática, Pontifícia Católica de São Paulo, PUC-SP, São Paulo, 2004.

Disponível em:<http://www.educadores.diaadia.pr.gov.br/arquivos/File/2010/artigos_teses/MAT EMAT ICA/Tese_curi.pdf> Acesso em: 29 Jun. 2019

LIMA, Willams dos Santos Rodrigues.; RODRIGUES, Polyana Marques Lima.;VIANA, Maria Aparecida Pereira. A educação a distância e o processo de ensinoaprendizagem: desafios e possibilidades. 2016, v.3, n.1 Disponível em: $\leq \mathrm{https}$ ://www.aunirede.org.br/revista/index.php/emrede/article/view/86/95> Acesso em: 26 Jun. 2019

MATTAR, João. Interações em ambientes virtuais de aprendizagem: Histórico e Modelos. TECCOGS, n. 9, 102 p, jan. - jun. 2014 Disponível em: 
$<$ http://www4.pucsp.br/pos/tidd/teccogs/artigos/2014/edicao_9/4-

interacoes_ambientes_virtuais_aprendizagem-joao_mattar.pdf $>$ Acesso em: 06 Jun 2019. 